\title{
PERAMALAN JUMLAH PENUMPANG ANGKUTAN BUS ANTAR KOTA ANTAR PROPINSI MENGGUNAKAN METODE HOLT WINTERS
}

\author{
Ida Ayu Masyuni ${ }^{1}$, Bayu Kusumo Nugroho ${ }^{2}$, Budi Mardikawati ${ }^{1}$, Dwi Wahyu Hidayat ${ }^{1}$ * \\ ${ }^{1}$ Manajemen Transportasi Jalan, Politeknik Transportasi Darat Bali, Jl. Cempaka Putih, Desa Samsam, \\ Kec.Kerambitan, Kab. Tabanan - Bali 80582, Indonesia \\ ${ }^{2}$ Manajemen Transportasi Jalan, Balai Pengelola Transportasi Darat Wilayah XI Propinsi Jawa Timur, Jl. \\ Gayungsari Barat No.11, Gayungan, Surabaya - Jawa Timur 60235, Indonesia \\ *dwi.wahyu@poltradabali.ac.id
}

\begin{abstract}
ABSTRAK
Terminal Mengwi yang berlokasi di Kabupaten Badung merupakan satu-satunya terminal Tipe A di Provinsi Bali sejak tahun 2012. Permasalahan umum pada terminal ini sejak awal beroperasi adalah tidak konsistenya jumlah penumpang dan bahkan cenderung menurun. Perlu ada penelitian untuk mengamati dan melakukan peramalan jumlah penumpang. Metode peramalan Holt-Winters digunakan dalam meramal jumlah kendaraan yang akan beroperasi di Terminal (keberangkatan) Mengwi. Dari hasil diketahui metode Additive Holt-Winters dapat melakukan smoothing hingga mendekati data aktual, dimana MAPE untuk smoothing data adalah 2,14\%. Namun, hasil peramalan 30 (tiga puluh) hari berikutnya belum bisa mendekati data aktual (terdapat kesalahan peramalan sebesar $14,21 \%$ ). Hal ini disebabkan karena metode Holt dan Winters murni menggunakan perhitungan dengan rumus yang sudah ditentukan, dan mengabaikan faktor luar, seperti tidak stabilnya keberangkatan penumpang menggunakan bus dari terminal Mengwi.
\end{abstract}

Kata Kunci: cat swarm optimization; metode holt-winters; peramalan

\section{FORECASTING THE NUMBER OF TRANSPORTATION BUS PASSENGERS INTER- CITY INTER PROVINCE USING THE HOLT-WINTERS METHOD}

\begin{abstract}
Mengwi Terminal, located in Badung Regency, is the only Type A terminal in Bali Province since 2012. The common problem with this terminal since its inception is that the number of passengers has been inconsistent and even tends to decline. There needs to be research to observe and forecast the number of passengers. The Holt-Winters forecasting method is used in predicting the number of vehicles that will operate at the Mengwi terminal (departure). From the results it is known that the Additive Holt-Winters method can perform smoothing up to the actual data, where the MAPE for data smoothing is $2.14 \%$. However, the results of forecasting the next 30 (thirty) days have not been able to approach the actual data (there is a forecast error of 14.21\%). This is because the Holt and Winters method purely uses calculations with a predetermined formula, and ignores external factors, such as unstable bus departures from Mengwi terminal.
\end{abstract}

Keywords: cat swarm optimization; forecasting; holt-winters method

\section{PENDAHULUAN}

Pulau Bali merupakan destinasi yang paling popular di Indonesia bagi wisatawan lokal maupun mancanegara. Sehingga bisa dipastikan ada banyak pergerakan transportasi dari dan ke Pulau Bali. Salah satu alternatif perjalanan dari dan ke bali dapat ditempuh dangan bus Antar Kota Antar Provinsi (AKAP) yang berawal dan berakhir di Terminal Mengwi. Terminal Mengwi merupakan satu-satunya terminal Tipe A yang ada di Provinsi Bali. Terminal ini berlokasi di Kabupaten Badung yang telah beroperasi sejak sejak tahun 2012. Permasalahan Umum yang ada pada terminal ini sejak awal beroperasi adalah tidak konsistenya jumlah penumpang, Berbeda dengan perjalanan menggunakan angkutan udara dan angkutan pribadi yang semakin tahun semakin meningkat, penggunaan angkutan penumpang bus AKAP dari dan ke kota-kota yang berada di luar pulau Bali, justru mengalami jumlah penumpang yang 
cenderung konstan atau bahkan semakin menurun. Dampak dari menurunnya jumlah penumpang adalah semakin menurunnya jumlah armada Bus yang beroperasi dari terminal Mengwi. Untuk meningkatkan pelayanan terminal sehingga bisa beroperasi secara optimal, salah satu cara ataupun alat yang dapat dipergunakan adalah dengan menggunakan metode peramalan.

Melihat tingginya kebutuhan akan peramalan penumpang di terminal khususnya keberangkatan dengan menggunakan Bus AKAP, penulis tertarik untuk melakukan penelitian peramalan kedatangan kendaraan di Terminal Mengwi dengan menggunakan metode HoltWinters. Diharapkan hasil penelitian ini dapat dapat membantu operasional terminal dalam menyiapkan.Beberapa metode telah dikembangkan untuk mendapatkan hasil terbaik untuk membantu peramalan. Dimulai dari metode paling sederhana, hingga memanfaatkan gabungan beberapa metode untuk mendapatkan hasil yang paling mendekati data actual. Salah satu metode peramalan yang banyak dipergunakan adalah Model Holt-Winters (Makridakis dkk., 1998). Model Holt-Winters menggunakan metode penghalusan eksponensial, suatu model peramalan rata-rata bergerak yang melakukan pembobotan terhadap data masa lalu dengan cara eksponensial sehingga data paling akhir mempunyai bobot atau timbangan lebih besar dalam rata-rata bergerak. Metode penghalusan eksponensial bersifat sederhana, intuitif dan mudah dipahami. Artinya, walaupun sederhana namun sangat berguna bagi peramalan pendek (shortterm forecasting) dari data time series yang panjang. Secara umum, model pemulusan eksponensial direkomendasikan sebagai sebuah teknik yang tidak kompleks dan ekonomis (inexpensive technique) dengan hasil ramalan yang cukup baik dalam variasi aplikasi yang luas.

\section{METODE}

Penelitian ini mengusulkan penggunaan metode Additive Holt-Winters untuk melakukan peramalan jangka pendek. Untuk mengetahui akurasi hasil peramalan, hasil dari penelitian ini akan dibandingkan dengan penggunaan metode Additive Holt-Winters klasik. Pelaksanaan penelitian ini dilakukan di Poleteknik Transportasi Darat Bali. dimana data uji digunakan adalah data kedatangan kendaraan bermotor di terminal Mengwi.

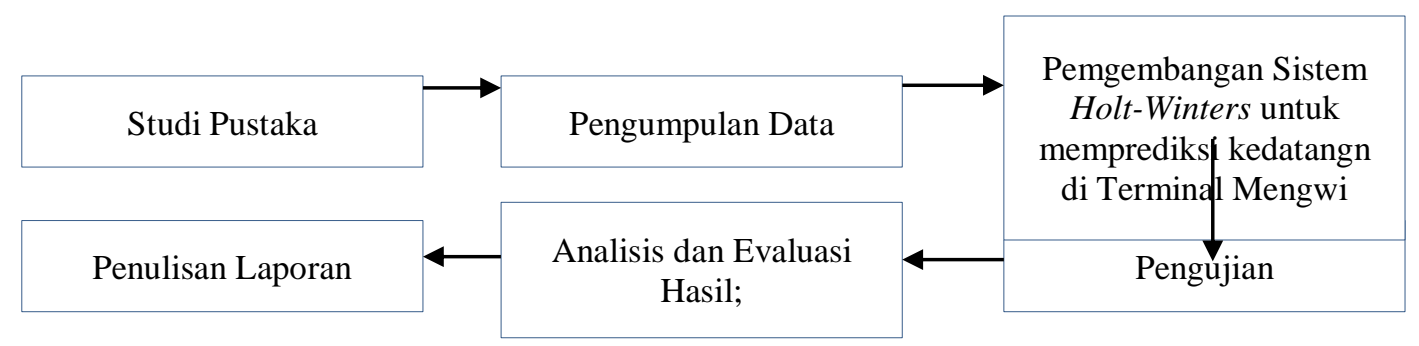

Gambar.1 Sistematika Penelitian

\section{HASIL DAN PEMBAHASAN}

Inputan awal, system akan menginisiasi matriks $\alpha, \beta$ dan $\gamma$ dengan membangkitkan data acak dengan kisaran data antara 0 dan 1 , sebagai mana tertera pada tabel 1 . Data decimal acak yang dapat didokumentasikan pada peneletian ini adalah 16 digit di belakang koma dari yang dihasilkan dan diproses oleh komputer. Data dimunculkan sedetail mungkin karena pembulatan akan sangat mempengaruhi hasil perhitungan di komputer. 
Tabel 1,

Inisialisasi $\alpha, \beta$ dan $\gamma$ dengan data acak

\begin{tabular}{rrr}
\hline $\boldsymbol{A}$ & $\boldsymbol{B}$ & $\boldsymbol{\Gamma}$ \\
\hline 0.72998309514341500 & 0.28476834134683000 & 0.87454937126263400 \\
0.71305952115959000 & 0.46047733627152100 & 0.10606134966011000 \\
0.89016244034988300 & 0.18233202898939500 & 0.69035321471370600 \\
0.16742198596204200 & 0.77650863591161800 & 0.48632705981449100 \\
\hline & & ..dst.
\end{tabular}

Tabel 2.

Hasil Smoothing masing-masing $\boldsymbol{\alpha}, \boldsymbol{\beta}$ dan $\boldsymbol{\gamma}$ dengan metode Holt-Winters

\begin{tabular}{lccccc}
\hline No & $A$ & $B$ & $\Gamma$ & MAPE & Ket. \\
\hline 1. & 0.8838642346952860 & 0.1508267435690760 & 0.0025369394801620 & $2.59 \%$ & \\
2. & 0.8921495236996570 & 0.0946092877949370 & 0.3814997875140840 & $2.91 \%$ & \\
3. & 0.8184643672915650 & 0.1524576966523850 & 0.1631287964148900 & $3.61 \%$ & \\
4. & 0.8087801695674840 & 0.1730741236069730 & 0.1626314297880300 & $3.83 \%$ & \\
5. & 0.7353148526365690 & 0.2043343866231540 & 0.0332678131093980 & $4.35 \%$ & \\
6. & 0.8713149189793880 & 0.1539671460243570 & 0.3206866251281680 & $3.40 \%$ & \\
& & & $\ldots$ & $\ldots$ & \\
& & & & dst. & Nilai \\
58. & 0.8953708470611920 & 0.0558062432420680 & 0.0243304743831440 & $2.14 \%$ & Terbaik \\
& & & $\ldots$ & $\ldots$ & \\
& & & & Dst & \\
\hline 100. & 0.8634829052065550 & 0.1870207196810940 & 0.0966410803627430 & $3.22 \%$ & \\
\hline
\end{tabular}

Tabel 3.

Hasil pengujian Cat terbaik menggunakan Holt-Winters yang dioptimasi dengan CSO

\begin{tabular}{cccccc}
\hline Tahun & Tanggal & Bulan & $\begin{array}{c}\text { Data } \\
\text { Keberangkatan } \\
\text { dari Terminal } \\
\text { Mengwi }\end{array}$ & $\begin{array}{c}\text { Hasil } \\
\text { Smoothing } \\
\text { dengan metode } \\
\text { Holt-Winters }\end{array}$ & $\begin{array}{c}\text { Absolute } \\
\text { Percentage } \\
\text { Error }\end{array}$ \\
\hline 2018 & 1 & 1 & 2906 & 0 & $0.00 \%$ \\
2018 & 2 & 1 & 3235 & 0 & $0.00 \%$ \\
2018 & 3 & 1 & 4585 & 0 & $0.00 \%$ \\
2018 & 4 & 1 & 1860 & 0 & $0.00 \%$ \\
2018 & 5 & 1 & 1460 & 0 & $0.00 \%$ \\
2018 & 6 & 1 & 1110 & 0 & $0.00 \%$ \\
2018 & 7 & 1 & 1468 & 0 & $0.00 \%$ \\
2018 & 8 & 1 & 771 & 2188.223653 & $0.00 \%$ \\
2018 & 9 & 1 & 1095 & 967.0390406 & $11.69 \%$ \\
2018 & 10 & 1 & 1073 & 825.2938723 & $23.09 \%$ \\
2018 & 11 & 1 & 977 & 730.3720445 & $25.24 \%$ \\
& & & & & \\
2019 & 27 & 10 & 1150 & 1172.534497 & $1.96 \%$ \\
2019 & 28 & 10 & 907 & 907.9798432 & $0.11 \%$ \\
2019 & 29 & 10 & 809 & 790.3601659 & $2.30 \%$ \\
2019 & 30 & 10 & 1104 & 1069.084327 & $3.16 \%$ \\
2019 & 31 & 10 & 1117 & 1108.226097 & $0.79 \%$ \\
\hline & & & & MAPE & $2.14 \%$ \\
\hline
\end{tabular}


Tabel 4.

Hasil peramalan 12 (dua belas) bulan berikutnya menggunakan Holt-Winters yang dioptimasi dengan CSO

\begin{tabular}{|c|c|c|c|c|c|}
\hline Tahun & Tanggal & Bulan & Data Pengujian & Hasil Peramalan & APE \\
\hline 2019 & 1 & 11 & 1233 & 1167.318486 & $5.63 \%$ \\
\hline 2019 & 2 & 11 & 1285 & 1132.77139 & $13.44 \%$ \\
\hline 2019 & 3 & 11 & 1478 & 1192.295971 & $23.96 \%$ \\
\hline 2019 & 4 & 11 & 1306 & 1295.841297 & $0.78 \%$ \\
\hline 2019 & 5 & 11 & 1155 & 1201.105991 & $3.84 \%$ \\
\hline 2019 & 6 & 11 & 1359 & 1384.05036 & $1.81 \%$ \\
\hline 2019 & 7 & 11 & 1356 & 1410.229486 & $3.85 \%$ \\
\hline 2019 & 8 & 11 & 1521 & 1427.431721 & $6.56 \%$ \\
\hline 2019 & 9 & 11 & 1434 & 1408.184179 & $1.83 \%$ \\
\hline 2019 & 10 & 11 & 1719 & 1113.734035 & $54.35 \%$ \\
\hline 2019 & 11 & 11 & 1481 & 1151.584228 & $28.61 \%$ \\
\hline 2019 & 12 & 11 & 1089 & 1130.068912 & $3.63 \%$ \\
\hline 2019 & 13 & 11 & 1086 & 1076.722567 & $0.86 \%$ \\
\hline 2019 & 14 & 11 & 1215 & 1146.796714 & $5.95 \%$ \\
\hline 2019 & 15 & 11 & 1184 & 1293.960183 & $8.50 \%$ \\
\hline 2019 & 16 & 11 & 1254 & 1231.138934 & $1.86 \%$ \\
\hline 2019 & 17 & 11 & 1313 & 986.1954917 & $33.14 \%$ \\
\hline 2019 & 18 & 11 & 1439 & 1160.983905 & $23.95 \%$ \\
\hline 2019 & 19 & 11 & 2123 & 1209.145163 & $75.58 \%$ \\
\hline 2019 & 20 & 11 & 1077 & 1279.580519 & $15.83 \%$ \\
\hline 2019 & 21 & 11 & 1127 & 1254.252905 & $10.15 \%$ \\
\hline 2019 & 22 & 11 & 1158 & 1148.291623 & $0.85 \%$ \\
\hline 2019 & 23 & 11 & 845 & 1192.107348 & $29.12 \%$ \\
\hline 2019 & 24 & 11 & 1084 & 1141.954502 & $5.08 \%$ \\
\hline 2019 & 25 & 11 & 1142 & 966.9087911 & $18.11 \%$ \\
\hline 2019 & 26 & 11 & 1029 & 992.3789171 & $3.69 \%$ \\
\hline 2019 & 27 & 11 & 1118 & 985.2549318 & $13.47 \%$ \\
\hline 2019 & 28 & 11 & 1082 & 1207.225016 & $10.37 \%$ \\
\hline 2019 & 29 & 11 & 1209 & 1294.36917 & $6.60 \%$ \\
\hline \multirow[t]{2}{*}{2019} & 30 & 11 & 1058 & 1243.947787 & $14.95 \%$ \\
\hline & & & & MAPE & $14.21 \%$ \\
\hline
\end{tabular}

Tabel 2 merupakan tahapan selanjutnya untuk menentukan kombinasi $\alpha, \beta$ dan $\gamma$ yang menghasilkan MAPE terendah untuk diproses menggunakan metode Holt-Winters untuk mendapatkan prediksi bulan November 2019. Hasil prediksi akan dibandingkan dengan data aktual yang diperoleh dari keberangkatan penumpang di terminal Mengwi untuk mengetahui hasil peramalan menggunakan metode Holt-Winters.

Hasil smoothing menggunakan proses Holt-Winters dengan nilai $\alpha, \beta$ dan $\gamma$ terbaik, dapat dilihat dalam table 3. Tabel 3 terkait keberangkatan di terminal Mengwi dianalisa per minggu atau per-7 (tujuh) hari, dengan demikian periode atau season yang dipergunakan dalam metode Holt-Winters untuk kasus keberangkatan dari terminal Mengwi menggunakan season $(\mathrm{L})=7$. Data 7 hari awal tidak diproses, melainkan menjadi inisiasi untuk menentukan nilai dari masing-masing variabel berikutnya. 
Tabel. 4 memperlihatkan hasil peramalan 30 hari berikutnya. Untuk peramalan tanggal 1 November dibandingkan dengan data aktual Keberangkatan penumpag, terdapat selisih aktual dan peramalah sejumlah 73 orang atau error peramalan sebesar $6.26 \%$. kesalahan terus mengecil hinggal selisih antara hasil peramalan dengan data aktual untuk bulan Agustus 2018 hanya sejumlah 13.97 point atau sebesar $0.75 \%$. Peramalan untuk data pengujian sudah semakin mendekati data aktual.

Perbandingan hasil peramalan untuk bulan yang sama dengan tahun yang berbeda dapat dilihat pada gambar.1 berikut :
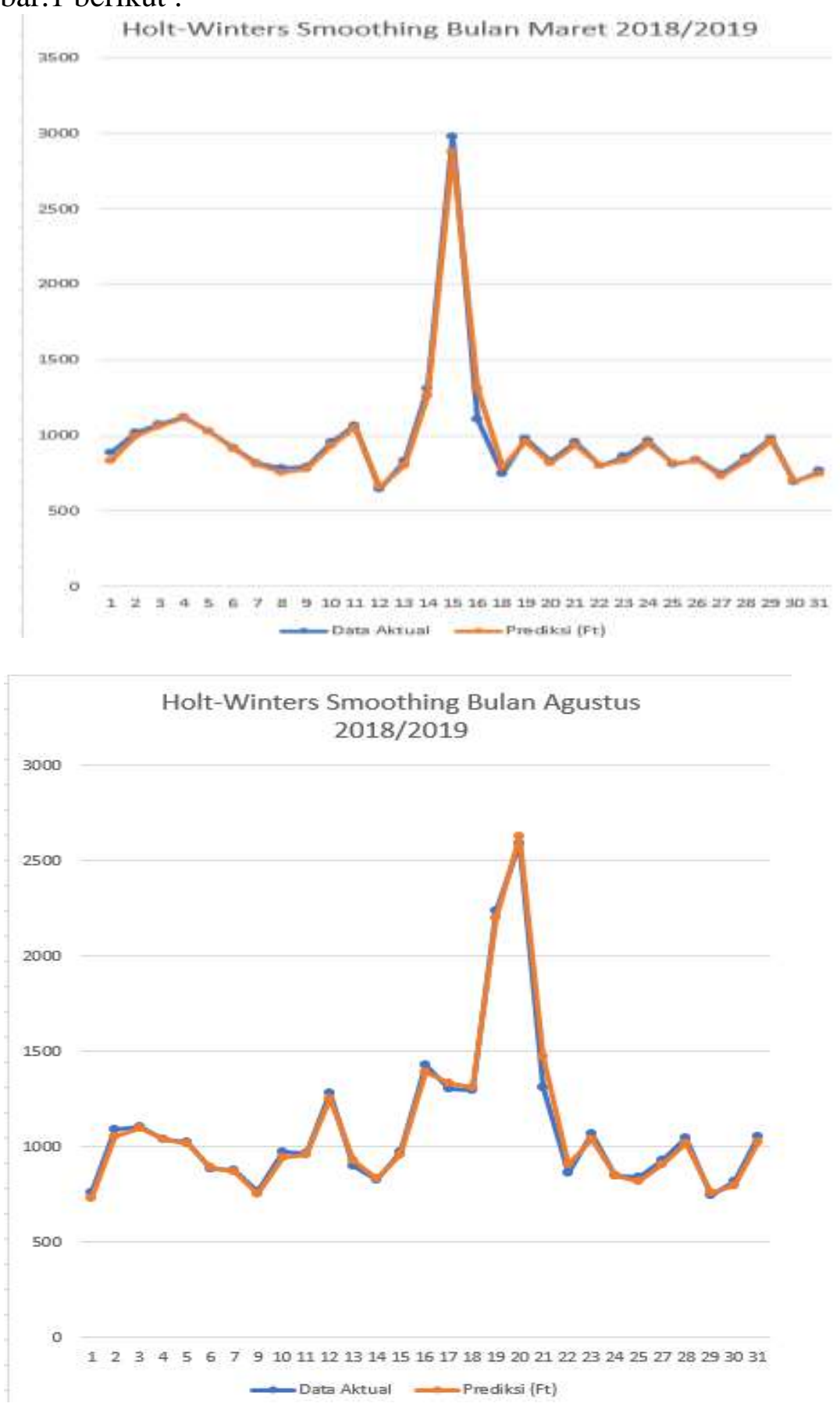

Gambar.1 Diagram perbandingan hasil smoothing perbulan Maret dan Agustus menggunakan metode Holt-Winters 
Gambar 2, menunjukkan bahwa hasil smoothing menggunakan metode Holt-Winters sudah mendekati data yang aktual Hasil peramalan 30 (tiga puluh) hari berikutnya belum bisa mendapatkan hasil yang mendekati data aktual (terdapat kesalahan peramalan sebesar $14.21 \%$ ). Hal ini disebabkan karena tidak stabilnya keberangkatan penumpang menggunakan bus dari terminal Mengwi. Trend penggunaan Bus cenderung menurun sehingga hasil peramalan menggunakan Holt-dan Winters rata-rata lebih rendah dari data aktual. Hal lain yang menyebabkan ketimpangan ini juga disebabkan karena metode Holt dan Winters mengabaikan faktor luar. Holt dan Winters murni menggunakan perhitungan dengan rumus yang sudah ditentukan.

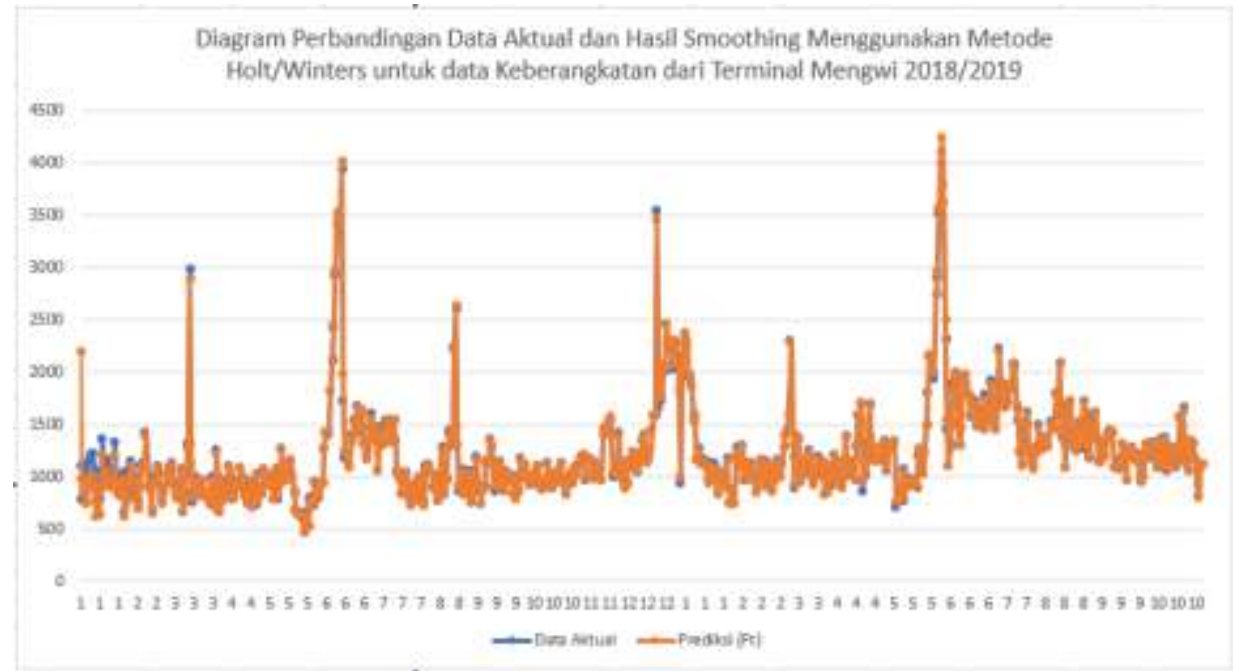

Gambar.2 Diagram perbandingan hasil smoothing keseluruhan data dari tahun 2018 s/d. 2019 menggunakan metode Holt-Winters

Uji Validasi ini digunakan untuk melihat korelasi antara jumlah penumpang (x) dengan jumlah kendaraan pertanggal (y). Uji ini menggunakan korelasi produk moment pearson $\left(r_{x y}\right)$. Dari pengolahan data awal (untuk uji validitas) diperoleh nilai seperti yang tersaji di Tabel.5 sebagai berikut:

Tabel .5 Nilai Hasil Pengolahan Data Awal (untuk Uji Validitas)

\begin{tabular}{llllll}
$\mathrm{N}$ & $\sum_{660} x$ & $\sum_{815.446} y$ & $\sum_{37.304} x y$ & $\sum_{49.992 .581} x^{2}$ & $\sum_{1.167 .610 .166} y^{2}$ \\
\hline
\end{tabular}

$r_{x y}=\frac{n\left(\sum x y\right)-\left(\sum x\right)\left(\sum y\right)}{\sqrt{\left(n\left(\sum x^{2}\right)-\left(\sum x\right)^{2}\right)\left(n\left(\sum y^{2}\right)-\left(\sum y\right)^{2}\right)}}$

$r_{x y}=\frac{(660 \times 49.992 .581)-(815.446 \times 37.304)}{\sqrt{\left(660 \times 1.167 .610 .166-(815.446)^{2}\right)\left((660 \times 2.221 .404)-(37.304)^{2}\right)}}=0,918$

Berdasarkan pengkategorian nilai validitas sesuai pendapat Guilford, maka nilai 0,918 berada pada rentang $0,80-1,00$. Sehingga diperoleh hasil validitas sangat tinggi (sangat baik).

\section{SIMPULAN}

Metode Additive Holt-Winters dapat melakukan smoothing hingga mendekati data aktual, dimana MAPE untuk smoothing data adalah 2.14\%. Hasil peramalan 30 (tiga puluh) berikutnya belum bisa mendapatkan hasil yang mendekati data aktual (terdapat kesalahan peramalan sebesar14.21\% ). Hal ini disebabkan karena tidak stabilnya keberangkatan penumpang menggunakan bus dari terminal Mengwi. Trend penggunaan Bus cenderung menurun sehingga hasil peramalan menggunakan Holt-dan Winters rata-rata lebih rendah dari data aktual. Hal lain yang menyebabkan ketimpangan ini juga disebabkan karena metode Holt 
dan Winters mengabaikan faktor luar. Holt dan Winters murni menggunakan perhitungan dengan rumus yang sudah ditentukan.

\section{DAFTAR PUSTAKA}

Andry Pratama Chiarli, Helmy Thendean. (2013) Penerapan Algoritma Genetika Pada Metode Winters Untuk Peramalan Nilai Tukar Mata Uang. Jurnal Ilmu Komputer dan Sistem Informasi Vol 1, No 1 Fakultas Teknologi Informasi Universitas Tarumanagara.

Arikunto, Suharsimi. (2002). Prosedur Penelitian, Suatu Pendekatan Praktik. Rineka Cipta. Jakarta.

Berlin, Kalekar, P. S. (2004). Time series forecasting using Holt-Winters exponential smoothing. Kanwal Rekhi School of Information Technologys.

Brown. Robert G. (1963). Exponential Smoothing for Predicting Demand. Arthur D Little Inc. Cambridge 42, Massachusetts.

Daniel. (2013). Studi tentang Pelayanan dan Pengujian Kelaikan Kendaraan bermotor di UPT Pengujian Kendaraan Bermotor Dinas Perhubungan Kota Samarinda. eJournal Administrasi Negara 1 (4): 1554-1568.

Eddy Herjanto. (2009). Sains Manajemen: Analisis Kuantitatif untuk Pengambilan Keputusan, Grasindo, Jakarta.

Eimutis Valakevicius, Mindaugas Brazenas. (2015). AppliCation of the Seasonal HoltWinters Model to Study Exchange Rate Volatility. Inzinerine Ekonomika-Engineering Ecomomic, 26(4), 384-390.

Evelina Padang, Gim Tarigan, Ujian Sinulingga. (2013). Peramalan Jumlah Penumpang Kereta Api Medan-Rantu Prapat dengan Metode Penghalusan Eksponansial HoltWinters. Saintia Matematika VOl. 1, No 2(2013), pp 161-174.

Guilford, J.P., Benjamin Druchter. (1956). Fundamental Statistic in Psyhology and Education. $5^{\text {th }}$ ed. Mc-Graw-Hill. Tokyo.

Hyndman, R., A. B. Koehler, J. Keith Ord \& R. D. Snyder. (2008). Forecasting With Exponential Smoothing: The State Space Approach. Springer Series in Statistics. Springer-Verlag Berlin Heidelberg.

Johan Agneman dan Roger Lindqvist. (2012). Forecasting Chargeable Hours at a Consulting Engineering Firm. Gothernburg Universiry PubliCation Electronic Archieve.

John E. Hanke; Arthur G. Reitsch; Dean W. Wichern. (2001). "Business Forecasting (7th Edition)", Prentice Hal International.

Liljana Ferbar Tratar. (2013). Improved Holt-Winters Method: A Case of Overnight Stays of Tourist in Republic of Slovenia. Economic and Business Review Vol. 16, No. 1, 5-17.

Maciej Szmit and Anna Szmit. (2012). Usage of Modified Holt-Winters Method in the Anomaly Detection of Network Traffic: Case Studies. Journal of Komputer Networks and CommuniCations, Volume 2012, Article ID 192913. 
Makridakis, Spyros dan Wheelwright, Steven C. (1998). Metode dan Aplikasi Peramalan. Binarupa Aksara Jakarta.

Mulyana. (2004), Analisis Data Time series. Universitas Padjadjaran: Bandung.

Newbeme, Joan H., Captain, USAF, MSC. (2007), Holt-Winters Forecasting: A Study of Practical AppliCation for Healthcare Managers. Defense Technical Information Center Virginia.

Oroushkani, M., Oroushkani, Y., Mansouri, M., Teshnehlab, M. (2013). A Novel Cat Swarm Optimization Algorithm for Unconstrained Optimization Problem. IJITCS vol.5 no.11 pp $32-41$.

Pichai Taneerananon, Verayuth Suanpaga, Nopadon Kronprasert, Taweesak Chawannakul, Theerachai Kompratya, Yodphol Tanabotiboon. (2005). An Evaluation of Effectiveness of Private Vehicle Inspection Process in Thailand. Journal of the Eastern Asia Society for Transportation Studies, Vol. 6 pp. 3482-3496.

Prasetya, Hery dan Lukiastuti, Fitri. (2009). Manajemen Operasi. Cetakan Pertama. Media Pressindo. Yogyakarta.

Sugiyono. (2009). Metode penelitian administrasi dilengkapi metode $R \& D$. Alfabeta, Bandung.

Undang-Undang Republik Indonesia Nomor 22 Tahun 2009 Tentang Lalu Lintas dan Angkutan Jalan

Sugiatro dan Harijono. (2000). Peramalan Bisnis. PT. Gramedia Pustaka Utama Jakarta.

Riz Rupert L. Ortiz. (2015). The Accuracy Rate of Holt-Winter Model with Particle Swarm Optimization in Forecasting Exchange Rates. Journal of Komputers Volume 11, Number 3, May 2016.

S. C. Chu, P. W. Tsai. (2007). Computational Intelligence Based On The Behavior Of Cats. International Journal of Innovative Computing, Information and Control, vol. 3, no. 1 : 163-173.

Sarah Gelper, Roland Fried dan Christope Croux. (2007). Robust Forecasting with Exponential and Holt-Winter Smoothing. Katholieke Universiteit Leuven. KBI 0718.

Sudipto Shankar Dasgupta, Prabal Mahanta, Rupam Roy, Ganapathy Subramanian, (2014). Forecasting Industry Big Data With Holt-Winters's Method from a Perspective of InMemory Paradigm.

Suhartono. (2008). Analisis Statistik dengan R. Lab Statistik Komputasi, ITS, Surabaya. 